\title{
O aprendizado de criminalística: interações entre as modalidades formal, informal e não-formal de educação
}

\author{
Learning criminalistics: interaction among informal, \\ non-formal and formal education
}

Rodrigo Grazinoli Garrido

\begin{abstract}
Garrido RG. O aprendizado de criminalística: interações entre as modalidades formal, informal e não-formal de educação. Saúde, Ética \& Justiça. 2010;15(1):10-5.

REsUmo: O artigo avalia o trânsito do conhecimento criminalístico entre as vertentes do ensino informal, não-formal e formal. Para tanto, foi realizado estudo descritivo transversal com alunos do Curso de Formação Profissional (CFP) de Peritos Criminais da Academia de Polícia Civil Sylvio Terra (ACADEPOL-PCERJ) e com alunos de Ensino Superior e Médio que buscaram mini-cursos na área de Criminalística. A partir da resposta de 202 questionários foi possível determinar claramente um ciclo informal-formal do ensino de Criminalística. Filmes e seriados de Televisão têm incrementado o interesse pela área, oferecendo um conhecimento prévio e levando à busca por cursos e palestras nãoformais. Os alunos do ensino formal também adquiriram conhecimentos prévios por meio destas mídias. Esse interesse pode ser aproveitado no Ensino Médio como fator de interdisciplinaridade e contextualização de conteúdos de ciências naturais. Já no Ensino Superior, deve propiciar o estabelecimento de cursos e habilitações em Criminalística. Dessa forma, devem-se formar profissionais com interesse pela área e, sobretudo, cidadãos mais conscientes.
\end{abstract}

DESCRITORES: Ciência forense; Criminalística; Modalidades de ensino.

INTRODUÇÃO

A Criminalística, como a conhecemos, teria seu início quando Hans Gross, no final do século XIX, propôs que os métodos da Ciência moderna fossem utilizados para solucionar casos criminais ${ }^{1}$. Hoje, reconhece-se que a ciência criminalística é a aplicação dos conhecimentos e tecnologias dos mais variados campos do saber com o intuito de reconhecer e interpretar indícios materiais, relativos ao crime ou à identidade do criminoso ${ }^{2}$. Essa Ciência pode ser dividida em várias áreas, entre elas: balística forense, documentoscopia, genética forense, exames em locais de crime, química forense, fonoaudiologia forense, entomologia forense, merceologia, informática forense e perícia contábil.

Durante sua evolução, várias foram as denominações doutrinariamente impróprias dadas à Criminalística ${ }^{3,4}$. Essa Ciência foi chamada de Criminologia Científica; Ciência Policial; Investigação

\footnotetext{
1 Biomédico; Perito Criminal, Diretor do Instituto de Pesquisa e Perícias em Genética Forense - IPPGF, Departamento Geral de Polícia Técnico-Científica/PCERJ.

Endereço para correspondência: Rodrigo Grazinoli Garrido. Instituto de Pesquisa e Perícias em Genética Forense - IPPGF, Departamento Geral de Polícia Técnico-Científica/PCERJ. Rua Marques de Pombal, 150. Rio de JaneiroRJ. CEP 20230-240. E-mail: rgrazinol@pcivil.rj.gov.br
} 
Garrido RG. O aprendizado de criminalística: interações entre as modalidades de educação.

Criminal Científica; Policiologia, as quais se aplicam também à administração policial e aos métodos gerais de elucidação de crimes. Na verdade, o termo Criminalística é oriundo da escola alemã, sendo utilizado por toda a Europa, nas palavras "Kriminalistik" e "Criminalistique".

Outra denominação muito utilizada na atualidade é Ciência Forense. Contudo, esta não é sinonímia de Criminalística em toda parte do mundo. Para Gialamas $^{5}$, Ciência Forense deve ser definida como a aplicação das ciências à matéria ou aos problemas legais cíveis, penais ou mesmo administrativos. Dessa forma, a Criminalística seria apenas um fragmento da Ciência Forense.

Ao discutir o ensino das diversas áreas da Criminalística deve-se ter em mente as vertentes formal, não-formal e informal de transmissão de conhecimento ${ }^{6}$. O ensino informal é aquele que ocorre, na maioria das vezes, de maneira não intencional a partir da experiência diária, de filmes e outros programas televisivos, da leitura de jornais e revistas. A vertente não-formal guarda relação com uma grande variedade de atividades organizadas fora do sistema educacional, de interesse específico, como os cursos livres ${ }^{7}$.

Já o ensino formal da Ciência Forense era, até bem pouco tempo no Brasil, encontrado apenas nos cursos de formação profissional de agentes de segurança pública, especialmente naqueles para Peritos Criminais. Contudo, recentemente, a Criminalística vem retornando às Universidades com a instituição de cursos de pós-graduação lato sensu nas diversas áreas da Ciência Forense e a partir de disciplinas oferecidas em cursos de graduação e de pós-graduação stricto sensu em que se ensinam os fundamentos das Ciências Forenses e a aplicação das diversas ciências ao desvendar de crimes. A possibilidade de formação formal independente dos cursos de formação profissional é essencial para o desenvolvimento desta Ciência e para a melhor qualificação dos Peritos e, assim, da prova técnica.

Além disso, após 2008, com a instituição do Assistente Técnico na ação penal ${ }^{8}$, tal formação deve ser importante para profissionais de nível superior autônomos contratados para acompanhar os trabalhos do Perito Criminal. Assim, seja por meio do laudo pericial oficial ou pelo parecer técnico oferecido pelo assistente, o ensino de Criminalística só vem contribuir com a evolução científica e, em última análise, com a justiça e a segurança pública.

Com isso, o trabalho propõe avaliar o trânsito do conhecimento criminalístico através das vertentes informal, não-formal e formal do ensino, a partir de um estudo descritivo transversal realizado com alunos do Curso de Formação Profissional (CFP) de Peritos Criminais da Academia de Polícia Civil Sylvio Terra (ACADEPOL-PCERJ) e com alunos de Ensino Superior e Médio que buscaram mini-cursos na área de Criminalística em eventos científicos ocorridos na Universidade Severino Sombra (USS) em Vassouras-RJ, no Instituto Federal de Educação, Ciência e Tecnologia (IFRJ) em Nilópolis-RJ e na Universidade Estadual Paulista (UNESP) em Botucatu-SP durante o ano de 2009. Os alunos com diferentes níveis de formação foram questionados sobre o conhecimento prévio e suas perspectivas na área de Criminalística.

\section{MATERIAIS E MÉTODOS}

Durante o ano de 2009, realizou-se estudo descritivo transversal com 202 participantes de cursos do ensino formal e não formal na área de Criminalística, assim divididos: 58 alunos, já graduados, da disciplina Introdução à Criminalística (12 horas-aula) do Curso de Formação Profissional (CFP) de Perito Criminal da ACADEPOL-PCERJ; 103 alunos de graduação participantes de dois mini-cursos de Criminalística Básica (6 horasaula ou 2 horas-aula) ministrados no XII Encontro Nacional de Biomedicina, realizado na UNESP em Botucatu-SP, e na VI Jornada de Biomedicina da USS em Vassouras-RJ e do mini-curso Introdução de Química ocorrido na XIII Semana de Tecnologia do IFRJ em Nilópolis-RJ e 41 alunos de Ensino Médio Técnico participantes do mesmo mini-curso Introdução à Química Forense (12 h/a).

Foram utilizados questionários estruturados com quatro perguntas que buscavam caracterizar as variáveis:conhecimentopréviosobreCriminalística; meio pelo qual se obteve primeiramente informação sobre o assunto; participação em outro curso da área; aplicabilidade de disciplinas da área de Criminalística no curso de graduação/técnico que cursava ou pelo qual era formado.

Os entrevistados foram abordados ao final dos cursos, quando receberam o questionário. Não foi 
Garrido RG. O aprendizado de criminalística: interações entre as modalidades de educação.

obrigatória a participação e não era necessária a identificação nos questionários.

Resultados e discussões

Ao discutir o ensino das diversas áreas da Criminalística deve-se ter em mente as vertentes formal, não-formal e informal de transmissão de informações ${ }^{6}$. Não se deve perder de vista, todavia, que estes ramos imbricam-se durante todo o processo de ensino-aprendizagem ${ }^{7}$. O ensino formal foi representado neste estudo pelo CFP de Perito Criminal, pré-requisito para a admissão na carreira de Perito Criminal da CERJ. Esta vertente diz respeito à estrutura organizada, hierarquizada, ligada a um sistema educacional com normas rígidas ${ }^{7}$. Primeiramente, ao final da Disciplina de Criminalística Básica, foi determinada a formação dos entrevistados: 23 engenheiros (Civil, Elétrica, Eletrônica, Florestal e Mecânica); 5 médicos veterinários; 5 biólogos; 12 químicos e engenheiros químicos; 5 físicos e 8 profissionais da área de informática.

Já entre os participantes do ensino não formal que foram entrevistados ao final do mini-curso Criminalística Básica, encontrou-se um total de 98 alunos de Biomedicina. Ainda no grupo de alunos do ensino não-formal, foram entrevistados 4 alunos de graduação em Química e 1 aluno de Física, além de 41 alunos do Ensino Médio Técnico em Química e Controle Ambiental os quais foram entrevistados após o mini-curso Introdução à Química Forense. Estes cursos visam informar e complementar a formação geral do interessado, funcionando assim, como ensino não-formal ${ }^{7}$.

Ao procurar determinar se os entrevistados possuíam algum conhecimento prévio sobre Criminalística, observaram-se percentuais elevados de graduados, alunos de graduação e alunos de Ensino Médio que já haviam ouvido falar a respeito da área (Graduados - 88\%; Alunos de Graduação - 99\%; Alunos do Ensino Médio Técnico - 100\%). Foi interessante perceber que este conhecimento prévio, apontado pelos alunos do ensino formal e não-formal de Criminalística, em todos os níveis de formação, adivinha em sua maior parte de seriados de televisão e filmes, como pode ser observado na Tabela 1.

Os seriados e filmes, certamente, além do ensino da Ciência Forense, participam na formação de uma imagem glamorosa e excitante do Cientista Forense. Esta imagem difere bastante daquela que a população tem de outros cientistas ${ }^{9}$. Diferentemente das vertentes formal e não-formal, o ensino que ocorre, na maioria das vezes, de maneira não intencional a partir da experiência diária, de filmes e outros programas televisivos, da leitura de jornais e revistas é considerado informal. Não obstante, a utilização do conteúdo deste tipo de mídia pode ser de grande valia para o ensino formal, contextualizando e dinamizando o conteúdo estudado ${ }^{10}$.

Como descrito por Gaspar ${ }^{7}$, as vertentes de ensino sobrepõem-se, podendo-se considerar, até mesmo, que o ensino informal apresente ação sinérgica, impulsionando a busca pela formação não-formal. Contudo, as experiências do dia-a-dia podem levar à construção de concepções espontâneas que, por vezes, se apresentam errôneas e incompletas. É o que acontece também com jornais e revistas que apresentaram grande participação no ensino

Tabela 1: Qual o meio que primeiro o informou a respeito de Criminalística?

\begin{tabular}{c|c|c|c|c}
\hline $\begin{array}{c}\text { Nível de } \\
\text { formação }\end{array}$ & $\begin{array}{c}\text { Seriados de } \\
\text { Tv e filmes }\end{array}$ & Livros & $\begin{array}{c}\text { Jornais e revistas } \\
\text { em qualquer mídia }\end{array}$ & $12 \%$ \\
\hline Graduado & $74 \%$ & $6 \%$ & $21 \%$ & $11 \%$ \\
\hline $\begin{array}{c}\text { Aluno de } \\
\text { Graduação }\end{array}$ & $65 \%$ & $3 \%$ & $5 \%$ & $7 \%$ \\
\hline $\begin{array}{c}\text { Aluno do Médio } \\
\text { Técnico }\end{array}$ & $85 \%$ & $3 \%$ & & \\
\hline
\end{tabular}


Garrido RG. O aprendizado de criminalística: interações entre as modalidades de educação.

informal da Criminalística (Tabela 1). Por mais séria que seja a mídia, esta, rotineiramente, se mostra superficial, incorreta e denota falta de rigor nas informações científicas ${ }^{7}$.

Deve-se observar com atenção o ensino formal representado aqui pelo CFP. Pois, sendo este um curso obrigatório para a carreira, falar que seriados e filmes estimularam sua busca é considerar que os mesmos meios também levaram os entrevistados a buscar o concurso público para o cargo de Perito Criminal. Tal análise foge à proposta do trabalho.

Aqueles que apontaram livros como fonte do conhecimento prévio não deixaram claro se tratavase de material didático ou ficcional. A ficção parece permear a Criminalística desde sua origem através de trabalhos de autores como Edgar Alan Poe, Conan Doyle, Mark Twain ${ }^{2}$. Os entrevistados que apontavam outros meios descreveram principalmente cursos e palestras que serão discutidos abaixo (Tabela 1).

Quando os entrevistados são questionados especificamente sobre a busca por outros cursos na área de Criminalística, observa-se que, entre aqueles já graduados, participantes do CFP o percentual ainda é pequeno (22\%). Contudo, este percentual é significativo quando se percebe que muitos destes realizam ou realizaram cursos de pós-graduação em áreas da Criminalística.

Uma vez que a Ciência Forense atual teve suas atividades iniciadas nos bancos das Universidades, com a criação em 1908 do Instituto de Polícia Científica na Universidade de Lausanne na França, mas que por uma série de fatores foi aos poucos se afastando da academia e sendo tutelada pelo Estado dentro das instituições policiais ${ }^{2}$, a procura por cursos de pós-graduação lato sensu em Criminalística ou nas diversas áreas da Ciência Forense e o oferecimento de disciplinas da área em cursos de graduação e de pós-graduação stricto sensu corrobora o retorno da Criminalística às Universidades. Já se tornaram realidades no Brasil, até mesmo, habilitações de Cursos de Bacharelado e projetos de cursos superiores inteiros na área da Criminalística ${ }^{6}$.

O percentual de entrevistados que já realizaram outros cursos ou assistiram palestra na área aumenta bastante entre os graduandos, alcançando $55 \%$. Talvez estes entrevistados estejam vivenciando, ainda na graduação, o ápice do ensino da Criminalística, já descrito. Contudo, o percentual retorna a níveis baixos entre os alunos dos cursos técnicos de nível médio (15\%).

Não se deve perder de vista que as atividades de Criminalística são praticadas por profissionais de nível superior, o que pode trazer algumas barreiras ao acesso de alunos do Ensino Médio nos cursos e palestras da área. Isto se reflete na busca pelos eventos acessíveis a este público, como é o caso do mini-curso Introdução Química Forense. Tal curso já ocorre há cinco anos consecutivos no IFRJ, somando mais de 500 alunos neste período. A participação do aluno do Ensino Médio se mostra importante como formação de massa crítica e como banco de futuros talentos na área. Além disso, vários agentes de segurança pública, nas esferas estadual e municipal brasileira ainda são de nível médio. Estes são direta ou indiretamente responsáveis pelo sucesso no trabalho do Perito, mas a Criminalística é muitas vezes negligenciada durante seus cursos e formação.

Uma vez que o interesse pela área se mostrou irrestrito e que a Criminalística é hoje uma Ciência bem estabelecida que se vale de conhecimentos da química, da física e da biologia, com o intuito de reconhecer e a interpretar indícios materiais, relativos ao crime ou à identidade do criminoso ${ }^{2,11}$, questionouse a aplicabilidade de disciplinas da área nos curso de graduação e técnico dos entrevistados.

Percentuais nunca menores que $83 \%$ dos entrevistados nos diversos níveis de formação acreditavam que disciplinas das variadas áreas da Criminalística deveriam fazer parte dos currículos de seus cursos. O profissional com conhecimento de Criminalística, além de atuar como Perito Criminal, pode vir a ser requisitado como Assistente Técnico nos Processos Criminais, com o advento da Lei 11690 de 20088.

No âmbito do Ensino Médio, há propostas interessantes como a de utilizar experimentos clássicos criminalísticos para o ensino de ciências naturais ${ }^{12}$. Esta prática busca oferecer interdisciplinaridade aos conteúdos escolares e contextualizar problemas, fazendo a ligação da temática ministrada com a vida cotidiana, como sugerido pelos Parâmetros Curriculares Nacionais ${ }^{13}$. Com isso, partindo do interesse pela Criminalística, se favorece o processo de ensino-aprendizagem da física, da química e da biologia.

Já nos cursos de graduação, a adequação 
Garrido RG. O aprendizado de criminalística: interações entre as modalidades de educação.

dos currículos de forma a introduzir disciplinas de Ciências Forenses está de acordo com os dispositivos da $\operatorname{LDB}^{14}$. Estes dispositivos permitem a flexibilização dos currículos de graduação a fim de definir diferentes perfis profissionais para as diversas áreas. Fora do Brasil, a existência de cursos de graduação em Ciência Forense já é uma realidade. No Chile, por exemplo, há instituições de ensino superior que oferecem diplomação em Criminalística em diferentes categorias, como Técnico, Licenciado e Engenheiro ${ }^{15}$. Nos Estados Unidos, o Departamento de Justiça estabelece as diretrizes para a formação de profissionais em Ciência Forense nas Instituições de Ensino Superior ${ }^{16}$.

O mesmo Departamento de Justiça dos EUA preconiza a formação de bacharel em Ciência Forense ou em alguma Ciência Natural (Química, Física, Biologia) como requisito para o profissional da Criminalística. Além disso, estimula a formação continuada em nível de Pós-graduação ${ }^{16}$.

O estabelecimento de cursos de graduação em Criminalística no Brasil demanda uma adequação dos próprios empregadores governamentais. Em muitos Estados e no Governo Federal o cargo de Perito Criminal só pode ser ocupado por profissionais com cursos de graduação específicos, especialmente na área das ciências naturais, como Ciências Biológicas, Biomedicina, Farmácia, Química, Física, Engenharia, Informática e outros. Assim, um possível Bacharel em Ciência Forense não teria acesso à função de perito, senão nos Estados que permitam formação superior em qualquer área para o cargo.

\section{Conclusão}

O interesse atual pela Criminalística está evidenciado na busca de ensino formal e não-formal desta ciência. Tal busca parece ser propiciada pelo ensino informal, oferecido principalmente por seriados de televisão, filmes e jornais, fechando um ciclo informal-formal de ensino.

Este interesse deve ser aproveitado ainda no Ensino Médio como fator de interdisciplinaridade e de contextualização para os conteúdos das ciências naturais. No que se refere ao ensino superior, a busca pelo ensino formal deve propiciar o estabelecimento de cursosdegraduaçãoepós-graduaçãoemCriminalística, além de habilitações em Ciência Forense em cursos já existentes, comojá ocorre em outros países. Além disso, uma vez que a Criminalística mostrou-se como área de interesse para diversos profissionais, não há mais como negligenciar a introdução de seus conteúdos nos variados cursos de formação profissional de agentes de segurança pública.

Dessa forma, a partir das diversas modalidades de ensino da Criminalística, é possível vislumbrar a boa formação de profissionais com interesse pela área e de cidadãos mais conscientes de seu papel na sociedade.

Garrido RG. Learning criminalistics: interaction among informal, non-formal and formal education. Saúde, Ética \& Justiça. 2010;15(1):10-5.

АвSTRACT: This paper analyzes the interaction among three different ways of acquiring Criminalistc knowledge: informal, non-formal and formal education. A descriptive cross-sectional study was carried out with the students from Forensic Scientists Professional Training Course (PTC) of Civil Police Academy Sylvio Terra (ACADEPOL-PCERJ), as well with the Higher Education and High School students who were applying for mini-courses in Criminalistics. Through 202 questionnaires, it was clearly detected an informal-formal educational cycle: Movies and TV series have been increasing the number of interested people in Criminalistics. Students from formal education grasp some knowledge through the media: this channel could be used as well in High School as an interdisciplinary and contextual technique to lecture about natural sciences and, in Higher Education, used to promote course and habilitation establishment in Criminalistics. In conclusion, it is expected a better formation as conscious citizens and an increase in the number of graduated students interested in this field.

KEY WORDS: Forensic science; Criminalistics; Learning modalities. 
Garrido RG. O aprendizado de criminalística: interações entre as modalidades de educação.

REFERÊNCIAS

1. Rabello E. Curso de criminalística. Porto Alegre: Sagra-Luzzatto; 1996.

2. Garrido RG, Giovanelli A. Criminalística - origem, evolução e descaminhos. Cad Sociais Aplicadas. 2009;5:43-60.

3. O'Hara CE, Osterburg JW. Introdução à criminalística. Rio de Janeiro: Fundo de Cultura; 1964.

4. Porto, G. Manual de criminalística. São Paulo: Sugestões Literárias; 1969.

5. Gialamas DM. Criminalistics. In: Siegel J, Knupfer G, Saukko P, editors. Encyclopedia of forensic sciences. Amsterdan: Elsevier; 2000. p. 471-47.

6. Garrido RG. O ensino de criminalística fora das instituições policiais: o que pensam nossos colegas? Informativo APERJ. 2007; 01 ago:6.

7. Gaspar A. O ensino informal de ciências: de sua viabilidade e interação como ensino formal à concepção de um centro de ciências. Cad Cat Ens Fis. 1992;9(2):157-63.

8. Brasil. Lei 11690 de 09 de junho de 2008. Altera dispositivos do Decreto-Lei no 3.689, de 3 de outubro de 1941 - Código de Processo Penal, relativos à prova, e dá outras providências. Brasília; 2008.

9. NSF - National Science Foundation. Congressional commission on the advancement of women and minorities in science, engineering, and technology development. Washington, DC:NSF; 2000.

10. Rocha MTL, Junior GFAD, Junior GIdeO, Messeder JC. Sugestão de abordagem para o ensino de ciências: o uso de um seriado de TV. Rev Ciên Ideias. 2010;1(2):1-12.

11. Garrido RG. Criminalística: uma grande área de atuação biomédica. Rev Biomédico. 2002;50:22-3.

12. Filho CRD, Antedomenico E. A perícia criminal e a interdisciplinaridade no ensino de ciências naturais. Química Nova Escola. 2010; 32(2):6772.

13. Brasil. Ministério da Educação e Cuktura. Parâmetros Curriculares Nacionais - PCN: ensino médio. Brasília, DF: Secretaria da Educação Média e Tecnológica, SEMTEC; 2002.

14. Brasil. Lei 9.304 de 20 de dezembro de 1996. Estabelece as diretrizes e bases da educação nacional. Brasília; 1996.

15. Herrera RGD. La formacion profissional e um criminalista desde la perspectiva de la educacion superior. In: Anais do XX Congresso Nacional de Criminalística, João Pessoa, PB, 2009.

16. National Institute of Justice (NIJ). Education and Taining in Forensic Science. A guide for forensic science laboratories, educational intitutions, and students. Washington,DC:NIJ; 2004.

Recebido em: 15/06/2010

Aprovado em: 28/06/2010 